\title{
Ionic elastomers based on carboxylated nitrile rubber (XNBR) and magnesium aluminum layered double hydroxide (hydrotalcite)
}

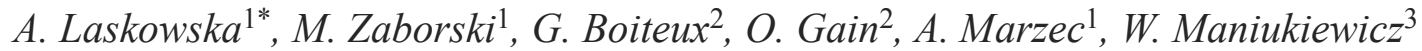 \\ ${ }^{1}$ Institute of Polymer and Dye Technology, Technical University of Lodz, Stefanowskiego 12/16, 90-924 Lodz, Poland \\ ${ }^{2}$ Ingénierie des Matériaux Polymères, Université Claude Bernard Lyon1, UMR CNRS 5223, 15 Bd A. Latarjet, 69622 \\ Villeurbanne, France \\ ${ }^{3}$ Institute of General and Ecological Chemistry, Technical University of Lodz, Zeromskiego 116, 90-924 Lodz, Poland
}

Received 31 October 2013; accepted in revised form 12 January 2014

\begin{abstract}
The presence of carboxyl groups in carboxylated nitrile butadiene rubber (XNBR) allows it to be cured with different agents. This study considers the effect of crosslinking of XNBR by magnesium aluminum layered double hydroxide (MgAl-LDH), known also as hydrotalcite (HT), on rheometric, mechano-dynamical and barrier properties. Results of XNBR/HT composites containing various HT loadings without conventional curatives are compared with XNBR compound crosslinked with commonly used zinc oxide. Hydrotalcite acts as an effective crosslinking agent for XNBR, as is particularly evident from rheometric and Fourier transform infrared spectroscopy (FTIR) studies. The existence of ionic crosslinks was also detected by dynamic mechanical analysis (DMA) of the resulting composites. DMA studies revealed that the XNBR/HT composites exhibited two transitions - one occurring at low temperature is associated to the $T_{\mathrm{g}}$ of elastomer and the second at high temperature corresponds to the ionic transition temperature $T_{\mathrm{i}}$. Simultaneous application of HT as a curing agent and a filler may deliver not only environmentally friendly, zinc oxide-free rubber product but also ionic elastomer composite with excellent mechanical, barrier and transparent properties.
\end{abstract}

Keywords: rubber, mechanical properties, carboxylated nitrile rubber, crosslinking, ionic elastomers

\section{Introduction}

Carboxylated acrylonitrile butadiene rubber (XNBR) is a terpolymer composed of acrylonitrile, butadiene and monomers containing carboxyl groups, such as acrylic and methacrylic acids. XNBR contains different active functional groups, including nitrile groups $(-\mathrm{CN})$, carboxylic groups $(-\mathrm{COOH})$, and alkene groups. All of these groups can participate in the crosslinking reaction, leading to the formation of different types of bonds, mainly covalent and ionic. Lateral carboxyl functionalities $-\mathrm{COOH}$ provide additional curing sites and make possible to use curing agents that can react with them con- tributing to the formation of ionic bonds [1, 2]. The conventional curing agents for XNBR that lead to ionic crosslinks are generally based on salts and oxides of multivalent metals (e.g., $\mathrm{ZnO}, \mathrm{MgO}, \mathrm{CaO}$ ), where the crosslinking reaction occurs through the formation of the corresponding salt of the metal ion [3]. Recently, it has been demonstrated that magnesium aluminum layered double hydroxides (MgAlLDHs) may act not only as a filler but also as a curative for XNBR, because of the Mg-Al-OH framework [4]. Pradhan et al. [5] reported that LDH has considerable potential for use as a reinforcing nanofiller in elastomers and also as a curing agent in car-

\footnotetext{
*Corresponding author, e-mail: anna.laskowska@hotmail.com (C) BME-PT
} 
boxylated elastomers. The mechanical properties of XNBR/decane sulfonate-modified LDH nanocomposites were enhanced due to the secondary interactions that occur between carboxylated rubber and layered double hydroxide filler. The use of LDHs has been already reported in elastomer composites of ethylene-propylene-diene rubber (EPDM) [5-9], acrylonitrile-butadiene rubber (NBR) [10], chloroprene rubber (CR) [11], silicone rubber (SR) [12, 13], and polyurethane PU [14-16] and solution styrenebutadiene rubber (SSBR) [17]. However, in the literature, there is no information on the impact of high loadings of unmodified magnesium aluminum layered double hydroxide used as a filler and a curing agent on the crosslinking process in XNBR. Layered double hydroxides (LDHs), also known as anionic clays, are minerals consisting of stacks of positively charged metal hydroxide layers (1:1, brucite-like) with interlayer anions that maintain the overall charge neutrality [18]. LDH is characterized by a layered structure and hexagonal particles with lateral dimensions of 50-400 nm. LDH particles are often very large and it is difficult to produce the single LDH sheets by the exfoliation because of strong electrostatic attraction between the layers and interlayer anions due to the surface charge density [19]. On the contrary to cationic clays that occur abundantly on the Earth, only a few anionic clays have been found in nature (e.g. hydrotalcite, $\left.\mathrm{Mg}_{6} \mathrm{Al}_{2}(\mathrm{OH})_{16} \mathrm{CO}_{3} \cdot 4 \mathrm{H}_{2} \mathrm{O}\right)$, and most LDHs are synthesized in the laboratory [20]. LDHs have attracted researchers attention due to their interesting properties, such as their layered structure, simplicity of synthesis, possibility of controlling particle size and aspect ratio by changing the reaction conditions and their highly designable characteristics. LDHs are widely used for the preparation of polyolefin nanocomposites with improved thermal properties, for example, the poly(ethylene terephthalate) (PET)/ LDH nanocomposites exhibited enhanced thermal stability relative to pure PET [21]. Recent research has demonstrated that incorporation of LDHs into a rubber matrix can remarkably enhance polymer properties such as mechanical, thermal and reduce gas permeability $[6,13]$. Some other physicochemical properties were also improved, compared to the one of neat polymers or composites that contain conventional fillers. Das et al. [10] developed a rubber composite based on zinc-stearate-modified LDH with NBR that does not require the incorporation of $\mathrm{ZnO}$ and stearic acid in the sulfuric curing system. In our work, the advantage of using unmodified magnesium/aluminum LDH in elastomer systems (XNBR or its hydrogenated counterpart HXNBR) lays in the possibility of full replacement of conventional metal oxide curatives used for functionalized elastomers (XNBR, HXNBR), particularly ZnO, which is believed to be harmful for the environment [22]. While crosslinking XNBR with a conventional sulfur vulcanizing system or $\mathrm{ZnO}$ is well known and commonly used, the application of magnesium aluminum layered double hydroxides MgAl-LDH for crosslinking process of XNBR is still a relatively new approach. This work presents the influence of hydrotalcite HT on the curing characteristics, mechanical and barrier properties of the XNBR composites. The results from XNBR/HT composites containing various filler loadings of $\operatorname{HT}(2.5,5$, 10,20 and 30 parts per hundred rubber, phr) without any conventional curatives are compared with the results from XNBR compound crosslinked with commonly used zinc oxide to demonstrate that this mineral has potential to be an interesting alternative to zinc oxide. The HT may provide the metal ions for metal-carboxylate curing, however it was found that quite high loadings of HT filler are needed for the preparation of composites with mechanical parameters that are comparable to those of $\mathrm{XNBR} / \mathrm{ZnO}$. However, the addition of large amounts of inexpensive and easily synthesized filler is advantageous because it reduces the cost of the final product.

\section{Experimental}

\subsection{Materials}

The carboxylated acrylonitrile-butadiene rubber XNBR used in this study was $\mathrm{Krynac}^{\mathbb{B}}$ X 750 (7 wt\% carboxyl groups content, $27 \mathrm{wt} \%$ acrylonitrile content, Mooney viscosity $\left(\left(\mathrm{ML}(1+4) 100^{\circ} \mathrm{C}\right) 47\right.$ and zinc oxide were supplied by LANXESS (Leverkusen, DE). Magnesium aluminum layered double hydroxide named hydrotalcite was obtained from Sigma Aldrich (652288, Schnelldorf, DE) was used in its unmodified form as a reinforcing filler for XNBR rubber and simultaneously played the additional role of a curative for XNBR. The compounding ingredients and the amounts used for this study are presented in Table 1. 
Table 1. Formulation of XNBR compounds [phr]

\begin{tabular}{|l|c|c|c|c|c|c|c|}
\hline \multicolumn{1}{|c|}{ Component } & X & XZnO5 & XHT2.5 & XHT5 & XHT10 & XHT20 & XHT30 \\
\hline XNBR & 100 & 100 & 100 & 100 & 100 & 100 & 100 \\
\hline HT & 0 & 0 & 2.5 & 5 & 10 & 20 & 30 \\
\hline ZnO & 0 & 5 & 0 & 0 & 0 & 0 & 0 \\
\hline
\end{tabular}

\subsection{Characterization of hydrotalcite}

\subsubsection{X-ray diffraction analysis (XRD)}

Room-temperature powder X-ray diffraction patterns were collected using a PANalytical X'Pert Pro MPD diffractometer in Bragg-Brentano reflecting geometry with $\left(\mathrm{CuK}_{\alpha}\right)$ radiation from a sealed tube (Almelo, Netherlands). Data were collected in the $2 \theta$ range of $2-70^{\circ}$ with a $0.0167^{\circ}$ step and $20-\mathrm{s}$ exposition per step.

\subsubsection{X-ray photoelectron spectroscopy (XPS)}

The surface elemental composition of HT was determined by X-ray photoelectron spectroscopy (XPS) analysis to confirm its stoichiometric composition. XPS spectra was recorded by using an X-ray photoelectron spectrometer Prevac (Rogow, Poland) equipped with hemispheric electron energy analyzer SES 2002, VG Scienta (Uppsala, Sweden) with an aluminum (mono) $\mathrm{K}_{\alpha}$ source $(1486.6 \mathrm{eV}$ ). The aluminum $\mathrm{K}_{\alpha}$ source was operated at $15 \mathrm{kV}$ and $25 \mathrm{~mA}$. For hydrotalcite sample, a high-resolution survey (pass energy $50 \mathrm{eV}$ ) was performed in the appropriate spectral regions. All core level spectra were referenced to the $\mathrm{C} 1 \mathrm{~s}$ neutral carbon peak at $284.6 \mathrm{eV}$.

\subsection{Preparation of $\mathrm{XNBR/HT}$ composites}

The samples were prepared using an internal mixer Brabender Measuring Mixer N50 (Duisburg, DE). The rubber compounds were processed at a rotor speed of $50 \mathrm{rpm}$ (revolutions per minute), and the initial temperature was set to $70^{\circ} \mathrm{C}$. After approximately 5 minutes of rubber mastication, the HT $(2.5,5,10,20$ and $30 \mathrm{phr})$ was added. The total time of compounding in the internal mixer was 20 minutes. Subsequently, the compounded rubbers were milled in a laboratory-scale open two-roll mixing mill.

\subsection{Curing behavior}

The curing characteristics of XNBR composites were determined using a MonTech Moving Die Rheometer MDR 3000 (Buchen, DE) at $160^{\circ} \mathrm{C}$ for 120 minutes. A sinusoidal strain of $7 \%$ and fre- quency of $1.67 \mathrm{~Hz}$ was applied. The optimum cure time $\left(t_{90}\right)$, scorch time $\left(t_{2}\right)$, minimum torque $\left(S_{\min }\right)$, maximum torque $\left(S_{\max }\right)$, and delta torque $(\Delta S)$ were determined from the curing curves. The mixed stocks were cured in a standard hot press at $160^{\circ} \mathrm{C}$ for $t_{90}$.

\subsection{Infrared spectroscopy ATR-FTIR}

Attenuated total reflection Fourier transform infrared (ATR-FTIR) spectra were recorded on a Thermo Scientific Nicolet 6700 FT-IR spectrometer (Waltham, MA, USA) at room temperature with a resolution of $4 \mathrm{~cm}^{-1}$ and a 64 -scan signal from $600-4000 \mathrm{~cm}^{-1}$ in absorbance mode.

\subsection{Dynamic mechanical analysis}

Dynamic mechanical analysis (DMA) was performed by means of a Dynamic Mechanical Analyzer TA Instruments Q 800 (New Castle, USA) operating in a tension mode at a frequency of $10 \mathrm{~Hz}$ in the temperature range of -80 to $100^{\circ} \mathrm{C}$ and at a heating rate of $2^{\circ} \mathrm{C} / \mathrm{min}$.

\subsection{Crosslink density}

The vulcanizates were subjected to equilibrium swelling in toluene for $48 \mathrm{~h}$ at room temperature. The swollen samples were then weighted on a torsion balance, dried in a dryer at a temperature of $60^{\circ} \mathrm{C}$ to a constant weight, and reweighed after $48 \mathrm{~h}$. The crosslinking density was determined based on Flory-Rehner's equation [23]. The Huggins parameter of the elastomer-solvent interaction $\chi$ was calculated from Equation (1) [24-26]:

$\chi=0.487+0.228 V_{\mathrm{r}}$

where $V_{\mathrm{r}}$ is the volume fraction of elastomer in the swollen gel.

\subsection{Stress-strain behavior}

The tensile properties were carried out with a ZWICK 1435 tensile testing machine of Zwick Roell Group (Ulm, DE). The moduli at 100, 200 and $300 \%$ elongation, tensile strength, and elongation at 
break were measured at room temperature with a crosshead speed of $500 \mathrm{~mm} / \mathrm{min}$ according to the PN-ISO 37-2005 standard. For this purpose, five different dumbbell-shaped specimens were tested, and the average value of each formulation was reported.

\subsection{Air permeability}

The through-plane air permeability of the composites was determined using the manometric method in accordance with the ASTM standard D1434, using circular samples of $30 \mathrm{~mm}$ in diameter and $1 \mathrm{~mm}$ in thickness. The tests were conducted using atmospheric air at room temperature.

\subsection{UV aging}

The UV aging studies were conducted for rubber composites using an UV2000, Atlas solar simulation chamber (Linsengericht, DE). The measurement lasted for $120 \mathrm{~h}$ and consisted of two alternately repeating segments with the following parameters: a day segment (radiation intensity of $0.7 \mathrm{~W} \cdot \mathrm{m}^{-2}$, temperature of $60^{\circ} \mathrm{C}$, duration of $8 \mathrm{~h}$ ), a night segment (without UV radiation, temperature of $50^{\circ} \mathrm{C}$, duration of $4 \mathrm{~h}$ ). After UV aging the stressstrain tests were performed. The UV aging coefficients $K$ were calculated according to the relationship Equation (2):

$K=\frac{(T S \cdot E B)_{\text {after aging }}}{(T S \cdot E B)_{\text {before aging }}}$

where $T S$ - tensile strength [MPa], $E B$ - elongation at break [\%]. The crosslink densities of the samples subjected to UV radiation were measured through a swelling method with toluene as the solvent, which was described above.

\subsection{Scanning electron microscopy (SEM)}

The fractured surfaces of the prepared materials were inspected using a scanning electron microscopy with a microscope SEM HITACHI S800 (Tokyo, Japan) at the accelerating voltage of $15 \mathrm{kV}$. Prior to SEM observations, liquid nitrogen-fractured surfaces of the composites were $\mathrm{Au} / \mathrm{Pd}$ sputtered (with a thickness of approximately $10 \mathrm{~nm}$ ).

\section{Results and discussion}

\subsection{Hydrotalcite surface properties}

Figure 1 presents the X-ray diffraction data for synthetic hydrotalcite. The interlayer distance $d$, calcu-

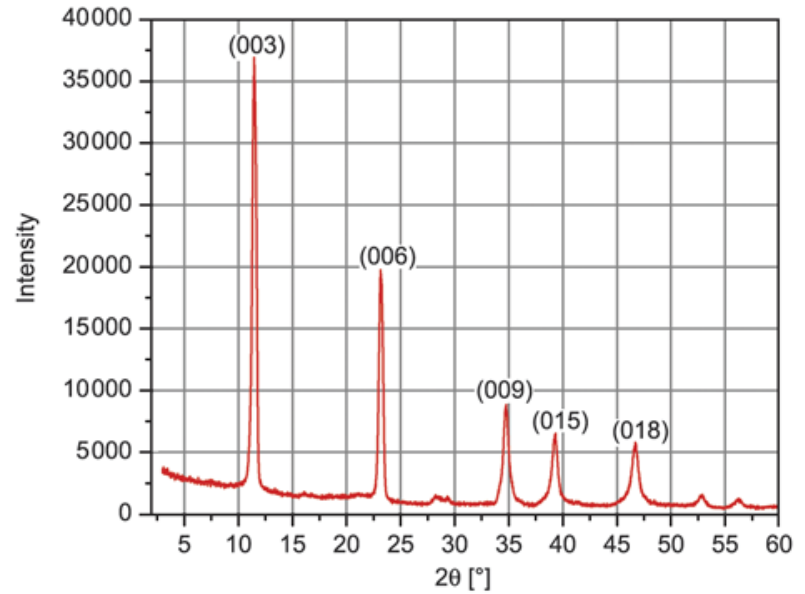

Figure 1. X-ray diffraction patterns of unmodified hydrotalcite HT

lated according to the Bragg's equation, was found to be $0.77 \mathrm{~nm}$. The XRD analysis of unmodified $\mathrm{MgAl}-\mathrm{CO}_{3}{ }^{2-}$ structure showed the basal reflections (003), (006), (009), which correspond to d-spacings of $0.77,0.34$ and $0.26 \mathrm{~nm}$ respectively. The sample of hydrotalcite did not contain any impurities, as generally, such materials are easily synthesized with a high degree of purity. The atomic content for hydrotalcite surface composition was determined by XPS analysis to confirm its stoichiometric composition. The total amount of magnesium, aluminum, oxygen and carbon was taken as $100 \%$, the atomic percentage of each element is given in Table 2. Based on the obtained data we could confirm that the ratio of magnesium to aluminum is approximately the same as stoichiometric ratio of the elements specified on the basis of chemical formula $\mathrm{Mg}_{6} \mathrm{Al}_{2}(\mathrm{OH})_{16} \mathrm{CO}_{3} \cdot 4 \mathrm{H}_{2} \mathrm{O}$. Also, the oxygen content is comparable to the typical content of the mineral. However, the atomic percentage of carbon on the

Table 2. XPS atomic content for hydrotalcite surface composition

\begin{tabular}{|c|c|c|c|c|}
\hline Atom & C & O & Al & Mg \\
\hline \multicolumn{5}{|c|}{ [atomic \%] } \\
\hline Hydrotalcite & 39.2 & 42.2 & 4.5 & 14.1 \\
\hline
\end{tabular}

Table 3. Binding energies of the main peaks for the hydrotalcite

\begin{tabular}{|l|c|c|}
\hline \multicolumn{2}{|c|}{$\begin{array}{c}\text { Photoelectron line positions } \\
{[\mathrm{eV}]}\end{array}$} & Chemical environment \\
\hline $\mathrm{Al} .2 \mathrm{p}$ & 73.9 & $\mathrm{Al}-\mathrm{OH}$ \\
\hline $\mathrm{Mg} 2 \mathrm{p}$ & 49.6 & $\mathrm{Mg}-\mathrm{OH}$ \\
\hline $\mathrm{O} 1 \mathrm{~s}$ & 531.6 & Oxygen bonds in hydroxyl groups \\
\hline $\mathrm{C} 1 \mathrm{~s}$ & 284.6 & Adventitious carbon \\
\hline $\mathrm{C} 1 \mathrm{~s}$ & 289.0 & $\mathrm{CO}_{3}{ }^{2-}$ \\
\hline
\end{tabular}


surface of the filler particles exceeds the expected value. This may result from a surface contamination with impurities derived from the decomposition of carbon compounds adsorbed from the air. Table 3 shows binding energies of the main peaks for hydrotalcite sample. For XPS C 1s there are two components, one appears at $E B=284.6 \mathrm{eV}$, which corresponds to so-called 'adventitious carbon' layer (C-C bonds, contamination) and second one appears at $E B=289.0 \mathrm{eV}$, which corresponds to inorganic carbonates, here $\mathrm{CO}_{3}{ }^{2-}$. Summarizing, surface analysis of hydrotalcite confirmed its stoichiometric composition and at the same time indicated that the surface of mineral is covered with a thin layer of carbon.

\subsection{Curing studies}

Figures 2 and 3 present the variation in the normalized elastic $\left(S^{\prime}\right)$ and viscous $\left(S^{\prime \prime}\right)$ components of the torque versus time, respectively. The curves were obtained from a MDR rheometer at $160^{\circ} \mathrm{C}$. Figure 2 shows the influence of an increase in the amount of

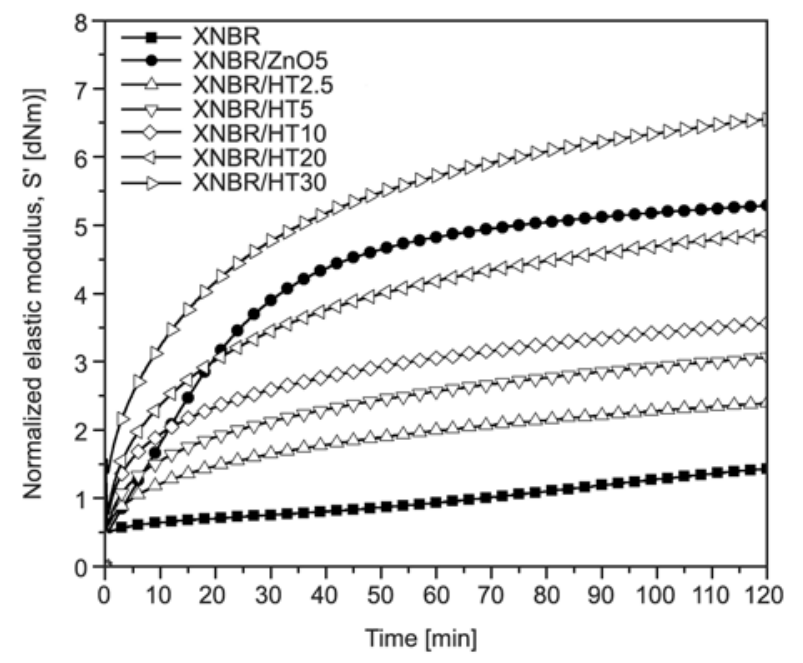

Figure 2. Normalized elastic component $\left(S^{\prime}\right)$ of the torque as a function of time for XNBR compounds crosslinked at $160^{\circ} \mathrm{C}$
HT on the curing curves compared with the curves for the crosslinking XNBR with $5 \mathrm{phr}$ of $\mathrm{ZnO}$ and pure XNBR. In the case of pure XNBR, self-crosslinking is possible through the formation of anhydride linkages between two carboxylic groups, however this process may occur at rather more severe conditions than $160^{\circ} \mathrm{C}[1,2,27]$. The curves show the continuous growth of the elastic component $S^{\prime}$ due to the increase of crosslinks of XNBR with $\mathrm{ZnO}$ as well as $\mathrm{HT}$ at each concentration (2.5, $5,10,20$ and $30 \mathrm{phr}$ ). The difference between maximum torque $S^{\prime}{ }_{\max }$ and minimum torque $S_{\text {min }}^{\prime}$, which is called the torque increment $\Delta S^{\prime}$ (Table 4), gradually rises with the content of HT which reflects an increment of the crosslink density and thus, an improvement in the mechanical properties. It can be clearly observed that an increase in the amount of HT leads to a greater number of crosslinks and consequently higher values of $S^{\prime}$. However, a plateau (Figure 2) was reached faster when $\mathrm{ZnO}$ was used as a curing agent, in the case of HT, the plateau was achieved more slowly during the analyzed reaction

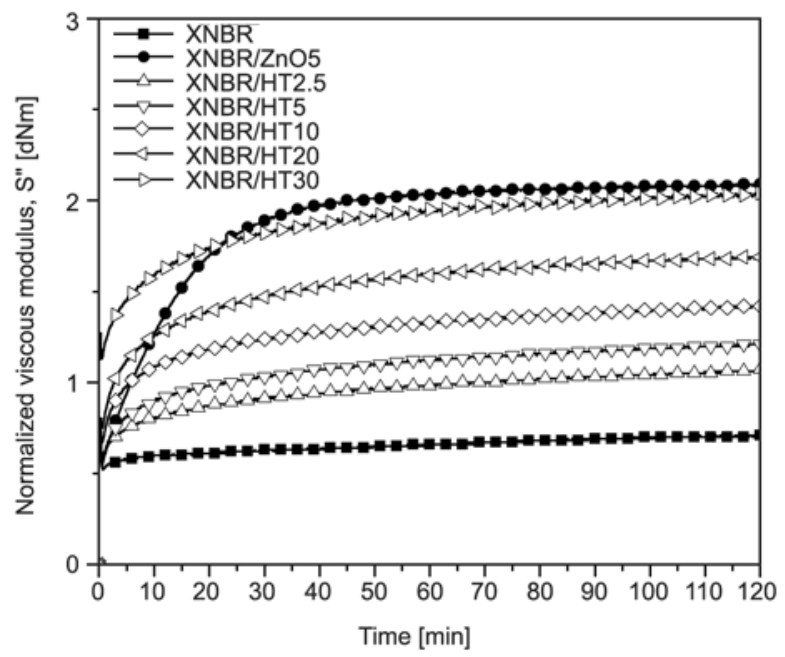

Figure 3. Normalized viscous component $\left(S^{\prime \prime}\right)$ of the torque as a function of time for XNBR compounds crosslinked at $160^{\circ} \mathrm{C}$

Table 4. Rheometric properties of XNBR/HT composites crosslinked at $160^{\circ} \mathrm{C}$

\begin{tabular}{|l|c|c|c|c|c|c|}
\hline \multicolumn{1}{|c|}{ Sample name } & $\begin{array}{c}\mathbf{S}_{\text {' }}^{\prime} \\
{[\mathbf{d N m}]}\end{array}$ & $\begin{array}{c}\mathbf{S}_{\text {max }}^{\prime} \\
{[\mathbf{d N m}]}\end{array}$ & $\begin{array}{c}\mathbf{\Delta} \mathbf{S}^{\prime} \\
{[\mathbf{d N m}]}\end{array}$ & $\begin{array}{c}\mathbf{t}_{\mathbf{2}} \\
{[\mathbf{m i n}]}\end{array}$ & $\begin{array}{c}\mathbf{t}_{\mathbf{9}} \\
{[\mathbf{m i n}]}\end{array}$ & $\begin{array}{c}\text { CRI } \\
{\left[\mathbf{m i n}^{-1} \mathbf{]}\right.}\end{array}$ \\
\hline X & 0.5 & 1.4 & 0.9 & 0.0 & 0 & - \\
\hline XZnO5 & 0.5 & 5.3 & 4.8 & 7.9 & 59 & 1.96 \\
\hline XHT2.5 & 0.6 & 2.4 & 1.8 & 27.6 & 90 & 1.60 \\
\hline XHT5 & 0.6 & 3.1 & 2.5 & 11.8 & 87 & 1.33 \\
\hline XHT10 & 0.8 & 3.6 & 2.8 & 7.0 & 83 & 1.32 \\
\hline XHT20 & 0.9 & 4.9 & 4.0 & 5.1 & 79 & 1.35 \\
\hline XHT30 & 1.4 & 6.6 & 5.2 & 4.1 & 77 & 1.37 \\
\hline
\end{tabular}

Note: $S_{\min }^{\prime}-$ minimal torque; $S_{\max }^{\prime}-$ maximum torque; $\Delta S^{\prime}$ - torque increment; $t_{2}$ - scorch time; $t_{90}$ - optimum cure time, CRI - cure rate index $100 /\left(t_{90}-t_{2}\right)$. 
time. However, the scorch time for XNBR/HT composites was shorter than that for $\mathrm{XNBR} / \mathrm{ZnO}$, and $t_{2}$ parameter (Table 4) was strongly dependent on the HT loading (decreasing with an increase in HT amount). As can be observed from the curves, there is practically no induction time. The compounds begin to vulcanize almost immediately, what is characteristic of crosslinking with metal oxides [28]. The presence of the MgAl-LDH also affects the viscosity of the compounds, resulting in higher values for normalized viscous component $S^{\prime \prime}$ (Figure 3). It is well known from the literature that the increase in viscous component $S^{\prime \prime}$ with time, is due to the formation of ionic bonds [27-31]. The curve corresponding to the curing with the $\mathrm{ZnO}$, which also forms ionic crosslinks, showed a similar behavior to that observed for XNBR cured with HT. For each HT concentration, $S^{\prime \prime}$ curves that increased with the reaction time were obtained, which is a characteristic of ionic vulcanization. Furthermore, as the HT loading increases, the value for the viscous component increases and here, $S^{\prime \prime}$ increased until it reached a plateau for each sample, regardless of the curative type used. In our opinion, curing with HT undoubtedly gives rise to ionic crosslinks. Table 4 presents the rheometric parameters of the XNBR compounds. From the values of $t_{90}$ it can be concluded that the optimum curing time slightly decreases with an increase in the amount of HT. The cure rate index (CRI) indicates that a faster curing reaction was achieved when $\mathrm{ZnO}$ was used compared to that of XNBR/HT. Based on the rheometric data rubber compounds were subsequently cured in a standard hot press at $160^{\circ} \mathrm{C}$, at the optimum cure time $\left(t_{90}\right)$ for the samples. It should be mentioned that crosslinking of XNBR with HT yields high trans-

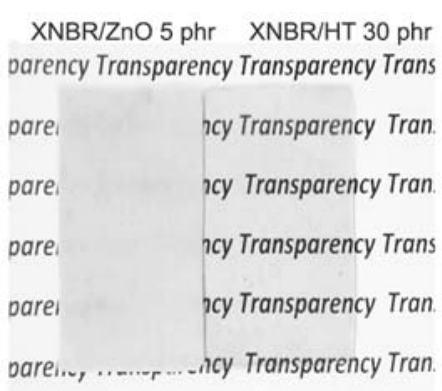

Figure 4. Opacity of XNBR with 5 phr of $\mathrm{ZnO}$ and optical transparency of XNBR with $30 \mathrm{phr}$ of HT

parent properties in the final composites, even when such high content as $30 \mathrm{phr}$ of HT is added (Figure 4). Optical transparency, which can be a desirable characteristic, was not observed in case of $\mathrm{XZnO} 5$ composite that was opaque. The transparency of rubber composites filled with LDHs has already been reported for NBR vulcanized with sulfur [10] and SSBR also vulcanized using a conventional sulfur cure system [17].

\subsection{FTIR studies}

Figures 5 and 6 show the ATR spectra of the sample without crosslinking agent (XNBR pure), the sample cured with $\mathrm{ZnO}(5 \mathrm{phr})$ and crosslinked with various amounts of $\operatorname{HT}(5,10,20$ and $30 \mathrm{phr})$ at $160^{\circ} \mathrm{C}$. Each spectra shows the existence of two principal absorption peaks for the XNBR compounds at 2928 and $2844 \mathrm{~cm}^{-1}$ due to the $-\mathrm{CH}_{2}$ groups on the rubber backbone. Another strong absorption peak that appears at $2237 \mathrm{~cm}^{-1}$ is due to the $\mathrm{CN}$-group in the acrylonitrile component. Those peaks remain unchanged during the crosslinking process for all investigated samples (Figure 5). The most important region of spectrum is the range between 1800 and $1500 \mathrm{~cm}^{-1}$, where peaks result from the $>\mathrm{C}=\mathrm{O}$

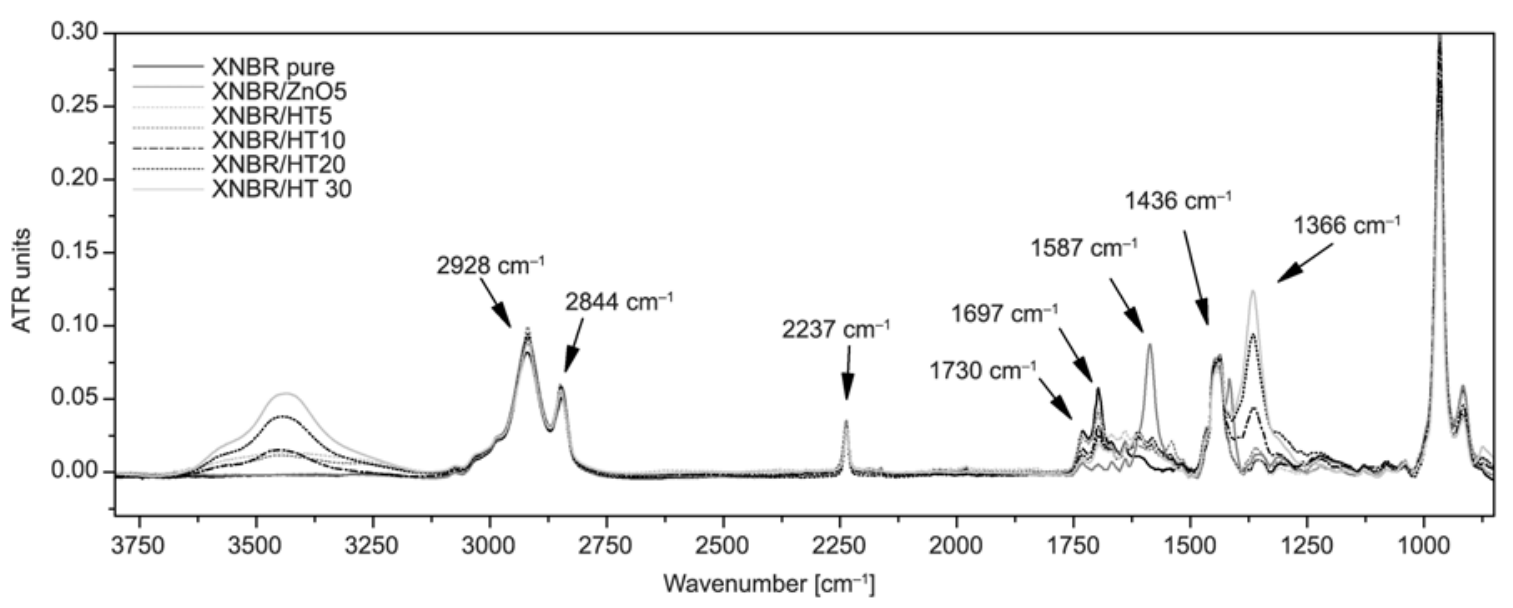

Figure 5. ATR spectra of XNBR compounds with various loadings of HT 


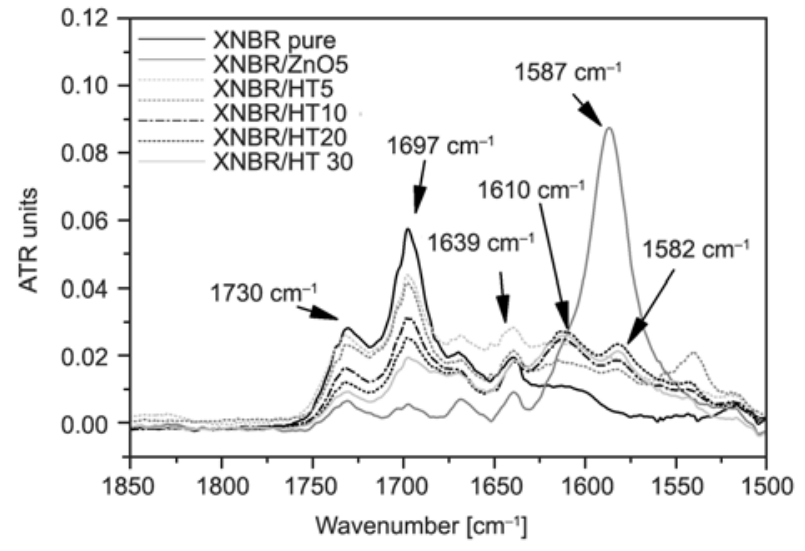

Figure 6. ATR spectra $\left(1850-1500 \mathrm{~cm}^{-1}\right)$ of XNBR containing various loadings of hydrotalcite HT

group of the carboxylic component in the rubber (Figure 6). The uncured sample shows two bands at 1697 and $1730 \mathrm{~cm}^{-1}$, which disappear in the sample crosslinked with $\mathrm{ZnO}$ and their intensities decrease when XNBR is cured with increasing amount of HT. This is due to the chemical change from weak acid to ionic bonds or slat formation. The first peak $\left(1697 \mathrm{~cm}^{-1}\right)$ is attributed to carbonyl stretching of hydrogen-bonded acid dimer, whereas the second one $\left(1730 \mathrm{~cm}^{-1}\right)$ is due to carbonyl stretching of monocarboxylic acid. The peak for $-\mathrm{COOH}$ appearing at a wavelength of $1697 \mathrm{~cm}^{-1}$ is reduced and a new peak at $1587 \mathrm{~cm}^{-1}$ is observed for the sample cured with $\mathrm{ZnO}$, that is attributed to the formation of ionic clusters between $-\mathrm{COO}^{-}$groups and $\mathrm{Zn}^{2+}$ ions of $\mathrm{ZnO}$, or. For samples crosslinked with HT the intensity of peaks at 1697 and $1730 \mathrm{~cm}^{-1}$, related to carboxylic groups, decreases with increasing content of metal hydroxide filler, what suggests that HT has evident influence in the dimer formation [1], and emphasizes the decrease of free acid groups with increasing HT amount [5]. According to the obtained data it can be assumed that the crosslinking occurs only with the $-\mathrm{COOH}$ groups of the elastomeric chain. The ionic bonds formed from the carboxylic groups and the magnesium aluminum layered double hydroxide generate some new bands at 1639,1610 and $1582 \mathrm{~cm}^{-1}$, which intensities slightly increase with HT content. According to the work of Pradhan, such a new band which appears at $1582 \mathrm{~cm}^{-1}$ corresponds to the $\mathrm{C}=\mathrm{O}$ stretching vibration of the metal carboxylate salt [5], that may be some type of confirmation of the chemical interaction between XNBR and HT. Table 5 shows the interpretation of existing peaks.

\subsection{Dynamic mechanical analysis (DMA)}

Figure $7 \mathrm{a}-7 \mathrm{c}$ show the variation of $\tan \delta$, storage modulus $\left(E^{\prime}\right)$ and loss modulus $\left(E^{\prime \prime}\right)$ with temperature for XNBR compounds at an oscillation frequency of $10 \mathrm{~Hz}$. The values of $T_{\mathrm{g}}, T_{\mathrm{i}}$ and $E^{\prime}$ are showed in Table 6. As expected, the $E^{\prime}$ for XNBR containing the highest amount of HT (30 phr) was the best of all tested samples, consequently the peak height of $\tan \delta$ was reduced significantly (Figure 7a, Table 6). The incorporation of increasing amounts of layered mineral gradually reduces the amplitude of $\tan \delta$ that indicates reinforcement by the filler which hinders the mobility of the rubber chains due to molecular confinement. The presence of HT at each content increases the curves of $E^{\prime}$ as well as the maximum for $E^{\prime \prime}$ and shifts $\tan \delta$ towards higher temperature in comparison to the neat XNBR, as a consequence of the increase in the crosslink density. The increase of storage modulus $E^{\prime}$ with increasing HT concentration is probably due to the strong interfacial interactions between HT particles and XNBR matrix. The neat XNBR sample gives only one tran-

Table 5. Peak assignments of FTIR spectra for XNBR composites

\begin{tabular}{|c|l|}
\hline $\begin{array}{c}\text { Wavenumber } \\
{\left[\mathbf{c m}^{-\mathbf{1}}\right]}\end{array}$ & \multicolumn{1}{c|}{ Assignment } \\
\hline 3420 & Stretching of $-\mathrm{O}-\mathrm{H}$ \\
\hline 2928 & Asymmetric stretching of the methylene group $-\mathrm{CH}_{2}$ \\
\hline 2844 & Symmetric stretching of the methylene group $-\mathrm{CH}_{2}$ \\
\hline 2237 & Stretching vibration of nitrile triple bonds in $\mathrm{XNBR}$ \\
\hline 1730 & Carbonyl stretching of monocarboxylic acid \\
\hline 1697 & Carbonyl stretching vibration of H-bonded $-\mathrm{COOH}$ group \\
\hline $1640-1670$ & Stretching of $\mathrm{C}=\mathrm{C}$ \\
\hline 1610 & Carbonyl stretching of magnesium hydroxycarboxylate salt \\
\hline 1587 & Asymmetric carbonyl stretching vibration of zinc carboxylate salt \\
\hline 1582 & Asymmetric carbonyl stretching vibration of magnesium carboxylate salt \\
\hline 1436 & CH deformation, in-plane deformation of methylene group \\
\hline 1366 & Asymmetric stretching of carbonate counter-ions $\mathrm{CO}_{3}{ }^{2-}$ \\
\hline
\end{tabular}



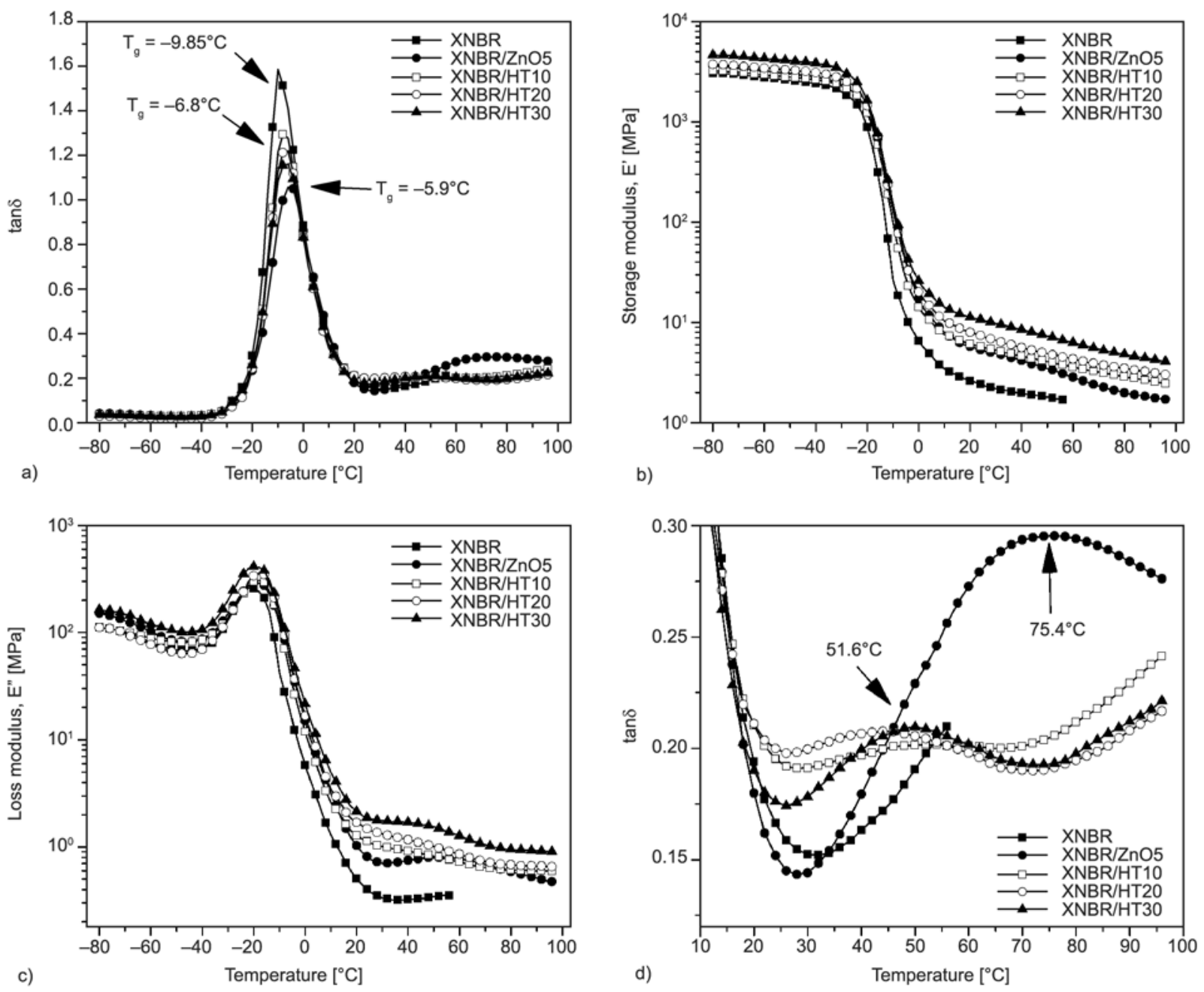

Figure 7. (a) Plot of $\tan \delta$, (b) plot of storage modulus $E^{\prime}$ (c) plot of loss modulus $E^{\prime \prime}$ versus temperature, (d) ionic transition region for XNBR composites. Vibration frequency, $10 \mathrm{~Hz}$

Table 6. Dynamic mechanical measurements at $10 \mathrm{~Hz}$ of XNBR/HT composites

\begin{tabular}{|l|c|c|c|c|c|}
\hline \multicolumn{1}{|c|}{ Sample name } & $\begin{array}{c}\mathbf{T}_{\mathbf{g}} \text { from } \mathbf{E}^{\prime \prime} \\
{\left[{ }^{\circ} \mathbf{C}\right]}\end{array}$ & $\begin{array}{c}\mathbf{T}_{\mathbf{g}} \text { from tan } \boldsymbol{\delta} \\
{\left[{ }^{\circ} \mathbf{C}\right]}\end{array}$ & $\begin{array}{c}\text { Height of tan } \boldsymbol{\delta} \\
{[-]}\end{array}$ & $\begin{array}{c}\mathbf{T}_{\mathbf{i}} \text { from tan } \boldsymbol{\delta} \\
{\left[{ }^{\circ} \mathbf{C}\right]}\end{array}$ & $\begin{array}{c}\mathbf{E}^{\prime} \text { at } \mathbf{2 5}^{\circ} \mathbf{C} \\
{[\mathbf{M P a}]}\end{array}$ \\
\hline $\mathrm{X}$ & -22.2 & -9.9 & 1.59 & - & 2.3 \\
\hline XZnO5 & -18.2 & -5.9 & 1.06 & 75.4 & 5.2 \\
\hline XHT10 & -18.0 & -6.8 & 1.30 & 45.6 & 5.6 \\
\hline XHT20 & -18.0 & -6.8 & 1.20 & 45.6 & 7.1 \\
\hline XHT30 & -18.0 & -6.8 & 1.16 & 51.6 & 10.4 \\
\hline
\end{tabular}

sition corresponding to the glass transition temperature of elastomer $\left(T_{\mathrm{g}}=-9.9^{\circ} \mathrm{C}\right)$, however it can be observed from Figure $7 \mathrm{~d}$ that there occurs an additional high temperature relaxation corresponding to ionic temperature transition $T_{\mathrm{i}}$. This is particularly evident for XNBR cured with $\mathrm{ZnO}\left(T_{\mathrm{i}}=75.4^{\circ} \mathrm{C}\right)$. This transition, is associated with the formation of ionic structures and occurs over a wide range of temperatures. In general, it is attributed to the hard phase arising from the formation of ionic clusters or conglomerates [27, 32]. Those clusters or ionic associ- ates begin to relax and weaken at the ionic transition temperature and consequently the elastomer loses its rigidity [28]. Figure $7 \mathrm{~d}$ shows that the $T_{\mathrm{i}}$ peak height slightly increases with the HT content in XNBR formulation as well as shifts towards higher temperatures up to $51.6^{\circ} \mathrm{C}$ when $30 \mathrm{phr}$ of HT is added. Table 6 shows the calculated values for the rubber glass transition and the ionic transition, obtained from the loss modulus $E^{\prime \prime}$ and $\tan \delta$ versus temperature curves. 


\subsection{Mechanical properties and crosslink density}

Table 7 shows the mechanical properties and the crosslink density values $(v)$ of the XNBR compounds cured with $\mathrm{ZnO}$ or alternatively with $\mathrm{HT}$ at various loadings. Apparently, an improvement in the tensile strength was observed for all vulcanizates filled with HT compared with the neat XNBR, what can be attributed to the existence of an ionic/polar interaction between HT and rubber. XNBR is a polar rubber that contains $-\mathrm{CN}$ and $-\mathrm{COOH}$ functionalities and appears to be compatible with polar fillers containing basic $-\mathrm{OH}$ groups, such as layered double hydroxides. Evidently HT exhibited a reinforcing effect on the XNBR, which raised the moduli at 100, 200 and $300 \%$ elongation, and the tensile strength of the XNBR/HT composites gradually increased with increasing amounts of HT. Moreover, the presence of HT remarkably reduced the elongation at break of the XNBR composites compared to the unfilled neat gum, probably due to the reduced free volume as a result of the interaction between the filler and the matrix, as well as the higher crosslink density. The incorporation of $\mathrm{ZnO}$ in XNBR produced an ionic elastomer with higher mechanical parameters what is probably related to stronger interactions between $\mathrm{ZnO}$ particles and rubber matrix. However, we can observe that HT also effectively participates in crosslinking reaction of XNBR and contributes to obtain strong and stiff elastomeric composites. The crosslink density is an important parameter influencing rubber properties. Table 7 shows that the tear strength and the $300 \%$ modulus of the rubber containing $10 \mathrm{phr}$ of HT are seen to be higher than those of the comparative neat rubber as well as XNBR cured with $\mathrm{ZnO}$. What is worth to note is that network density of vulcanizates remarkably increases with an increasing level of HT in the XNBR compounds. The trend observed here is in harmony with that recorded in the case of the tensile strength and the increment in torque $\Delta S^{\prime}$, which is further confirmation that layered double hydroxide may play a role not only as a reinforcing filler but also as a curative agent for functionalized elastomers such as XNBR.

\subsection{Barrier properties}

The dependence of air permeability on the XNBR composition is presented in Figure 8. An uncrosslinked, neat XNBR sample was too weak mechanically and was destroyed almost immediately by the pressure of the gas at the very beginning of the experiment. It is evident that the air permeability was reduced with increasing layered double hydroxide content, what is surely related to the higher network density of the samples. The barrier properties of XNBR are enhanced the most by the incorporation of $30 \mathrm{phr}$ of hydrotalcite, the same sample that was characterized by the highest amount of ionic crosslinks. The effect of reduced permeability may be explained through strongly restricted the motion of

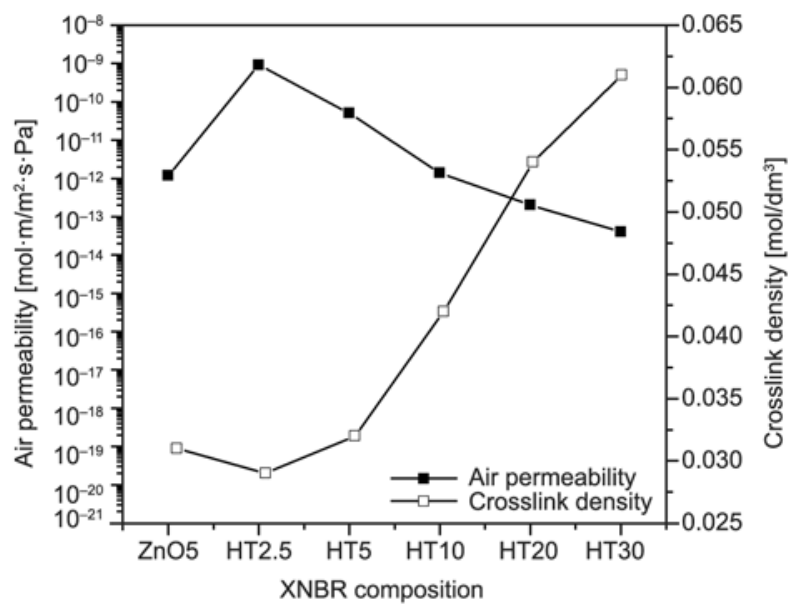

Figure 8. Dependence of air permeability and crosslink density on XNBR composition

Table 7. Mechanical properties of XNBR/HT composites

\begin{tabular}{|c|c|c|c|c|c|c|c|}
\hline Sample name & $\begin{array}{c}\mathrm{SE}_{100} \\
\text { [MPa] }\end{array}$ & $\begin{array}{c}\mathrm{SE}_{200} \\
\text { [MPa] }\end{array}$ & $\begin{array}{c}\mathrm{SE}_{300} \\
\text { [MPa] }\end{array}$ & $\begin{array}{c}\text { TS } \\
\text { [MPa] }\end{array}$ & $\begin{array}{c}\text { EB } \\
{[\%]}\end{array}$ & $\begin{array}{c}\mathbf{F} \\
{[\mathrm{N} / \mathrm{mm}]}\end{array}$ & $\begin{array}{c}v \\
{\left[\mathrm{~mol} / \mathrm{dm}^{3}\right]}\end{array}$ \\
\hline $\mathrm{X}$ & 0.7 & 0.7 & 0.6 & 0.7 & 1401 & 3.1 & - \\
\hline $\mathrm{XZnO5}$ & 1.4 & 1.9 & 2.3 & 19.0 & 500 & 6.3 & 0.031 \\
\hline XHT2.5 & 1.0 & 1.2 & 1.4 & 4.5 & 727 & 8.2 & 0.029 \\
\hline XHT5 & 1.2 & 1.7 & 2.3 & 8.4 & 688 & 9.2 & 0.032 \\
\hline XHT10 & 1.9 & 2.8 & 4.1 & 14.5 & 536 & 12.8 & 0.042 \\
\hline ХHT20 & 2.5 & 4.3 & 6.4 & 16.0 & 542 & 12.6 & 0.054 \\
\hline ХHT30 & 3.3 & 5.8 & 8.3 & 18.6 & 519 & 14.3 & 0.061 \\
\hline
\end{tabular}

$S E_{100,200,300}$ - stress modulus at 100, 200 and $300 \%$ elongation, $T S$ - tensile strength, $E B$ - elongation at break, $F-$ tear strength, $v$ - crosslink density 
rubber chains by hydrotalcite particles that results in reducing the diffusion of the gas molecules. Another reason may be that the impermeable hydrotalcite layers forced a tortuous pathway, which retarded the diffusion of the gas molecules [33].

\subsection{Resistance to $\mathrm{UV}$ radiation}

Table 8 summarizes the mechanical properties and crosslink densities of XNBR samples exposed to ultraviolet light. XNBR generally has poor resistance to ozone, UV radiation and weathering because double bonds are present in polybutadiene segment of the chemical backbone. Inorganic compounds, such as metal oxides provide effective UV screening. The presence of the layered double hydroxide enhanced UV stability of XNBR material compared with that of the corresponding gum rubber matrix or that crosslinked with zinc oxide, as the aging factor $K$ increased gradually with the increase in the filler content. The effect was more pronounced for samples containing the highest concentration, $30 \mathrm{phr}$ of HT. From the obtained data we may conclude that the addition of HT improves UV stability of XNBR composites.

\subsection{Scanning electron microscopy analysis (SEM)}

The micrographs of filler particles and XNBR composite containing $30 \mathrm{phr}$ of HT obtained from scanning electron microscopy are shown in Figure 9a$9 d$. Figure $9 b$, shows that hydrotalcite is characterized by a layered structure and hexagonal-shaped particles with lateral dimensions of $50-400 \mathrm{~nm}$. A high layer charge density makes LDH extremely difficult to exfoliate or delaminate into single sheets compared to cationic clays. However, because of the polar surface of LDH, a good compatibility with XNBR (containing polar groups such as nitrile, car- boxyl), is expected. Moreover, dispersed HT particles may form strong bonds with rubber matrix, possibly through the chemical interaction between the acidic $-\mathrm{COOH}$ functionality of XNBR and the basic $-\mathrm{OH}$ groups on the layered metal hydroxide particle surface [5]. It is evident from Figure 9c, 9d that HT particles forms agglomerates with an average size of about $5 \mu \mathrm{m}$. It can be said that melt mixing of HT with rubber matrix does not provide good enough dispersion, as some agglomerates were detected, the state of HT dispersion is not uniform throughout the whole mass of rubber material. Because of high content of HT in rubber matrix (30 phr), which is necessary to obtain composites with high mechanical properties as well as great number of crosslinks, the problem of uniform distribution of HT particles in elastomer matrix appears.

\section{Conclusions}

In this study the effect of magnesium aluminum layered double hydroxide, also called hydrotalcite (MgAl-LDH, HT), on the crosslink reaction, mechanical and barrier properties of XNBR were examined. It was found that the HT effectively participates in the crosslinking reaction of XNBR and contributes to obtaining strong and stiff elastomeric composites. The dynamic mechanical analysis revealed a remarkable enhancement in the storage moduli and increase in glass transition temperature when HT is present in the XNBR matrix. The increase in crosslink density and the improvement in mechanical properties of XNBR/HT composites may result from the following types of interactions between: (a) acidic functionalities of XNBR and basic hydroxyl groups existing on the filler sheets, (b) polar functional groups of XNBR and polar surface of filler, (c) $-\mathrm{COOH}$ and metal ions provided

Table 8. Mechanical properties of XNBR/HT composites subjected to UV radiation

\begin{tabular}{|l|c|c|c|c|c|c|c|}
\hline Sample name & $\begin{array}{c}\mathbf{S E}_{\mathbf{1 0 0}} \\
{[\mathbf{M P a}]}\end{array}$ & $\begin{array}{c}\mathbf{S E}_{\mathbf{2 0 0}} \\
{[\mathbf{M P a}]}\end{array}$ & $\begin{array}{c}\mathbf{S E}_{\mathbf{3 0 0}} \\
{[\mathbf{M P a}]}\end{array}$ & $\begin{array}{c}\mathbf{T S} \\
{[\mathbf{M P a}]}\end{array}$ & $\begin{array}{c}\mathbf{E B} \\
{[\mathbf{\%}]}\end{array}$ & $\begin{array}{c}\mathbf{K} \\
{[-]}\end{array}$ & $\begin{array}{c}\mathbf{v} \\
{\left[\mathbf{m o l}_{\mathbf{d}} \mathbf{\mathbf { d m } ^ { \mathbf { 3 } } ]}\right.}\end{array}$ \\
\hline X & 0.9 & 0.9 & 0.9 & 1.2 & 1202 & - & 0.019 \\
\hline XZnO5 & 1.9 & 2.5 & 3.3 & 6.0 & 400 & 0.2 & 0.028 \\
\hline XHT2.5 & 1.5 & 1.7 & 2.0 & 2.8 & 510 & 0.2 & 0.049 \\
\hline XHT5 & 1.6 & 1.9 & 2.3 & 3.2 & 470 & 0.2 & 0.051 \\
\hline XHT10 & 2.0 & 2.7 & 3.8 & 5.3 & 460 & 0.3 & 0.066 \\
\hline XHT20 & 3.2 & 4.7 & 6.1 & 8.0 & 420 & 0.4 & 0.094 \\
\hline XHT30 & 3.8 & 5.6 & 7.2 & 11.1 & 480 & 0.6 & 0.107 \\
\hline
\end{tabular}

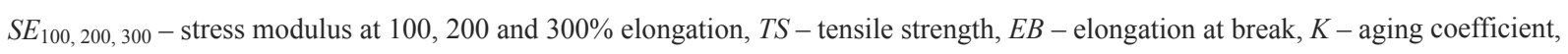
$v-$ crosslink density. 


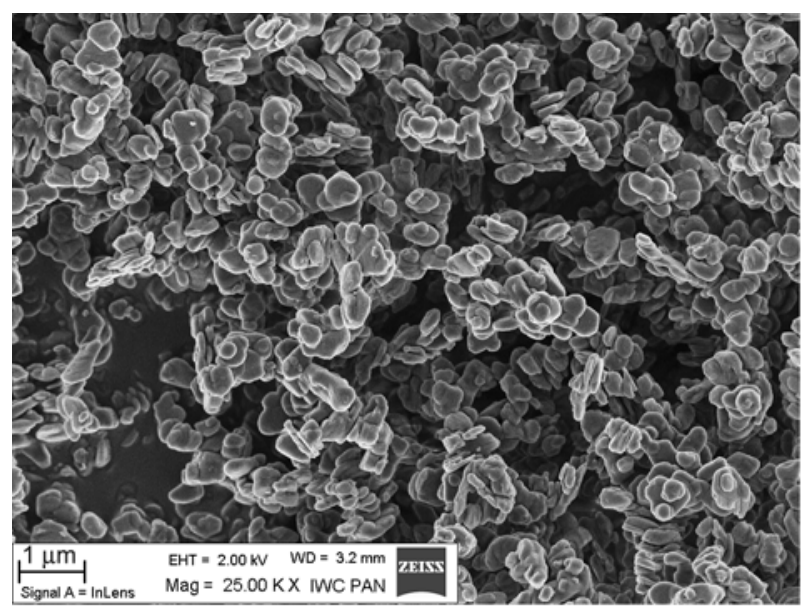

a)

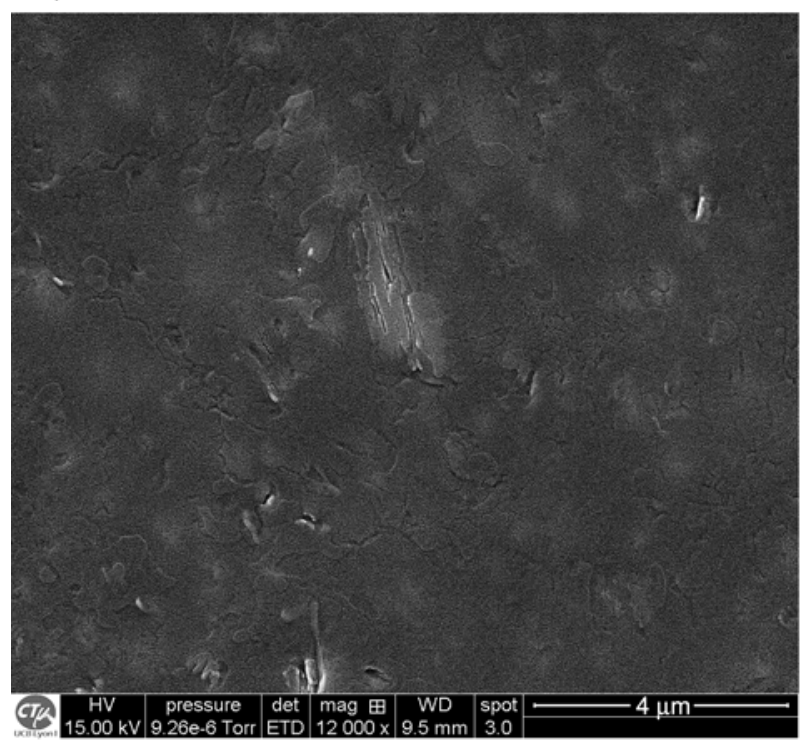

c)

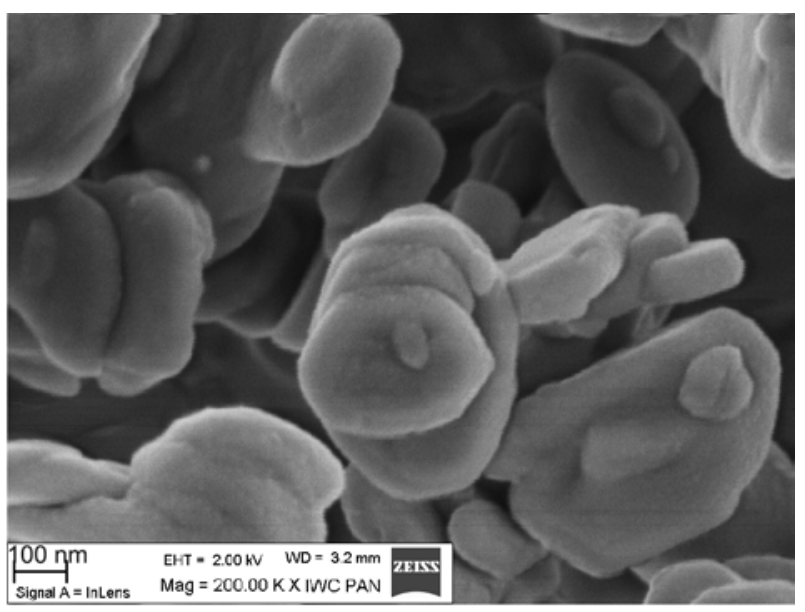

b)

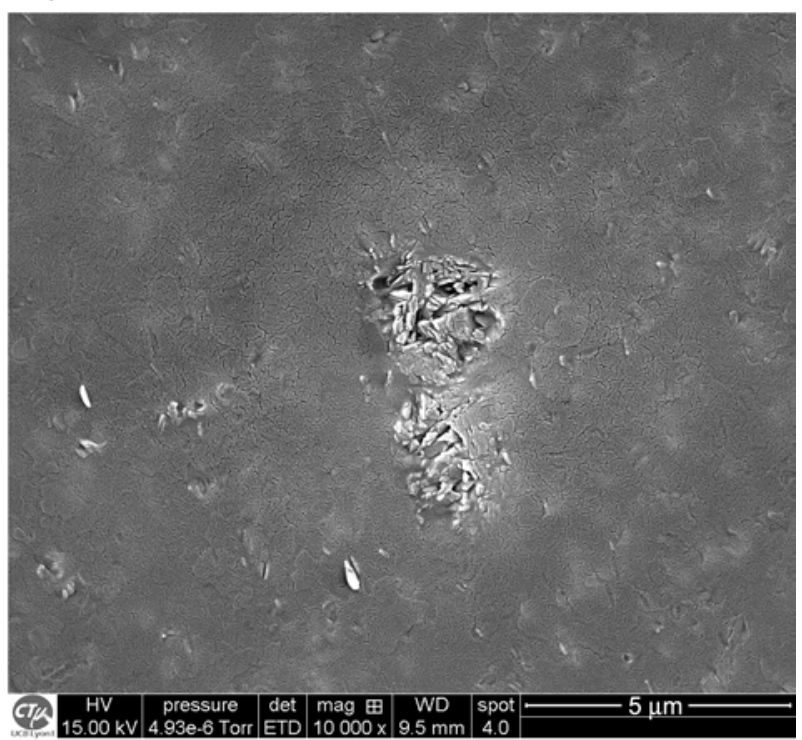

d)

Figure 9. SEM micrographs of (a), (b) particles of hydrotalcite HT, (c), (d) XNBR composite with 30 phr of hydrotalcite HT

by HT (ionic bonds). The simultaneous application of HT as a curing agent and a filler may deliver not only an environmentally friendly, zinc oxide-free rubber product but also an ionic elastomer composite with excellent mechanical, barrier and transparent properties. However, obtaining material with aforementioned parameters requires high loadings of HT. Application of large amounts of an inexpensive and easily synthesized filler is economically beneficial due to the reduction of the cost of the final product.

\section{Acknowledgements}

The authors wish to acknowledge the Center of Electronic Microscopy of UCB Lyon 1 (Mr. Thierry Tamet \& Mr. Pierre Alcouffe) for performing electronic microscopy analysis and also to Mr. Flavien Melis for his valuable suggestions and help.

\section{References}

[1] Brown H. P.: Carboxylic elastomers. Rubber Chemistry and Technology, 30, 1347-1386 (1957). DOI: $10.5254 / 1.3542762$

[2] Thakur V., Das A., Mahaling R. N., Rooj S., Gohs U., Wagenknecht U., Heinrich G.: Influence of layered double hydroxides on the curing of carboxylated nitrile rubber with zinc oxide. Macromolecular Materials and Engineering, 294, 561-569 (2009). DOI: $10.1002 /$ mame.200900083

[3] Ibarra L., Marcos-Fernández A., Alzorriz M.: Mechanistic approach to the curing of carboxylated nitrile rubber (XNBR) by zinc peroxide/zinc oxide. Polymer, 43, 1649-1655 (2002).

DOI: $\underline{10.1016 / \mathrm{S} 0032-3861(01) 00734-0}$ 
[4] Costa F. R., Pradhan S., Wagenknecht U., Bhowmick A. K., Heinrich G.: XNBR/LDH nanocomposites: Effect of vulcanization and organic modifier on nanofiller dispersion and strain-induced crystallization. Journal of Polymer Science Part B: Polymer Physics, 48, 2302-2311 (2010). DOI: $10.1002 /$ polb.22116

[5] Pradhan S., Costa F. R., Wagenknecht U., Jehnichen D., Bhowmick A. K., Heinrich G.: Elastomer/LDH nanocomposites: Synthesis and studies on nanoparticle dispersion, mechanical properties and interfacial adhesion. European Polymer Journal, 44, 3122-3132 (2008). DOI: 10.1016/j.eurpolymj.2008.07.025

[6] Acharya H., Srivastava S. K., Bhowmick A. K.: Synthesis of partially exfoliated EPDM/LDH nanocomposites by solution intercalation: Structural characterization and properties. Composites Science and Technology, 67, 2807-2816 (2007).

DOI: 10.1016/j.compscitech.2007.01.030

[7] Acharya H., Srivastava S. K., Bhowmick A. K.: A solution blending route to ethylene propylene diene terpolymer/layered double hydroxide nanocomposites. Nanoscale Research Letters, 2, 1-5 (2006).

DOI: $10.1007 / \mathrm{s} 11671-006-9020-\mathrm{x}$

[8] Kumar B., Rana S., Singh R. P.: Photo-oxidation of EPDM/layered double hydroxides composites: Influence of layered hydroxides and stabilizers. Express Polymer Letters, 1, 748-754 (2007). DOI: 10.3144/expresspolymlett.2007.103

[9] Wang D-Y., Das A., Leuteritz A., Mahaling R. N., Jehnichen D., Wagenknecht U., Heinrich G.: Structural characteristics and flammability of fire retarding EPDM/layered double hydroxide (LDH) nanocomposites. RSC Advances, 2, 3927-3933 (2012).

DOI: $10.1039 / C 2 R A 20189 \mathrm{E}$

[10] Das A., Wang D-Y., Leuteritz A., Subramaniam K. H., Greenwell C. H., Wagenknecht U., Heinrich G.: Preparation of zinc oxide free, transparent rubber nanocomposites using a layered double hydroxide filler. Journal of Materials Chemistry, 21, 7194-7200 (2011). DOI: $10.1039 /$ C0JM03784B

[11] Das A., Costa F. R., Wagenknecht U., Heinrich G.: Nanocomposites based on chloroprene rubber: Effect of chemical nature and organic modification of nanoclay on the vulcanizate properties. European Polymer Journal, 44, 3456-3465 (2008).

DOI: $10.1016 /$ j.eurpolymj.2008.08.025

[12] Pradhan B., Srivastava S. K., Ananthakrishnan R., Saxena A.: Preparation and characterization of exfoliated layered double hydroxide/silicone rubber nanocomposites. Journal of Applied Polymer Science, 119, 343-351 (2011).

DOI: $10.1002 /$ app.32614
[13] Pradhan B., Srivastava S. K., Bhowmick A. K., Saxena A.: Effect of bilayered stearate ion-modified Mg-Al layered double hydroxide on the thermal and mechanical properties of silicone rubber nanocomposites. Polymer International, 61, 458-465 (2012). DOI: $10.1002 /$ pi.3218

[14] Kotal M., Srivastava S. K.: Structure-property relationship of polyurethane/modified magnesium aluminium layered double hydroxide nanocomposites. International Journal of Plastics Technology, 15, 6168 (2011).

DOI: $10.1007 / \mathrm{s} 12588-011-9006-0$

[15] Guo S., Zhang C., Peng H., Wang W., Liu T.: Structural characterization, thermal and mechanical properties of polyurethane/CoAl layered double hydroxide nanocomposites prepared via in situ polymerization. Composites Science and Technology, 71, 791-796 (2011).

DOI: 10.1016/j.compscitech.2010.12.001

[16] Kotal M., Srivastava S. K., Bhowmick A. K.: Thermoplastic polyurethane and nitrile butadiene rubber blends with layered double hydroxide nanocomposites by solution blending. Polymer International, 59, 2-10 (2010).

DOI: $10.1002 / \mathrm{pi} .2686$

[17] Das A., George J. J., Kutlu B., Leuteritz A., Wang D-Y., Rooj S., Jurk R., Rajeshbabu R., Stöckelhuber K. W., Galiatsatos V., Heinrich G.: A novel thermotropic elastomer based on highly-filled LDH-SSB composites. Macromolecular Rapid Communications, 33, 337-342 (2012).

DOI: $10.1002 /$ marc. 201100735

[18] Reichle W. T.: Synthesis of anionic clay minerals (mixed metal hydroxides, hydrotalcite). Solid State Ionics, 22, 135-141 (1986).

DOI: 10.1016/0167-2738(86)90067-6

[19] Leroux F., Besse J-P.: Polymer interleaved layered double hydroxide: A new emerging class of nanocomposites. Chemistry of Materials, 13, 3507-3515 (2001). DOI: $10.1021 / \mathrm{cm} 0110268$

[20] Xu Z. P., Zhang J., Adebajo M. O., Zhang H., Zhou C.: Catalytic applications of layered double hydroxides and derivatives. Applied Clay Science, 53, 139-150 (2011). DOI: 10.1016/j.clay.2011.02.007

[21] Cui W., Jiao Q., Zhao Y., Li H., Liu H., Zhou M.: Preparation of poly(ethylene terephthalate)/layered double hydroxide nanocomposites by in-situ polymerization and their thermal property. Express Polymer Letters, 6, 485-493 (2012).

DOI: 10.3144 /expresspolymlett.2012.51

[22] Heideman G., Noordermeer J. W. M., Datta R. N., van Baarle B.: Effect of zinc complexes as activator for sulfur vulcanization in various rubbers. Rubber Chemistry and Technology, 78, 245-257 (2005).

DOI: $10.5254 / 1.3547881$ 
[23] Flory P. J., Rehner J.: Statistical mechanics of crosslinked polymer networks II. Swelling. Journal of Chemical Physics, 11, 521-526 (1943).

DOI: $10.1063 / 1.1723792$

[24] Lenko D., Schlögl S., Temel A., Schaller R., Holzner A., Kern W.: Dual crosslinking of carboxylated nitrile butadiene rubber latex employing the thiol-ene photoreaction. Journal of Applied Polymer Science, 129, 2735-2743 (2013).

DOI: $10.1002 / A P P .38983$

[25] Zaborski M., Kosmalska A., Gulinski J.: Silica modified by use of organosilanes as a filler for carboxylate butadiene-acrylonitrile rubber. Kautschuk und Gummi Kunststoffe, 58, 354-357 (2005).

[26] Przepiórkowska A., Chrońska K., Zaborski M.: Chrometanned leather shavings as a filler of butadiene-acrylonitrile rubber. Journal of Hazardous Materials, 141, 252-257 (2007).

DOI: $10.1016 /$ j.jhazmat.2006.06.136

[27] Eisenberg A., Hird B., Moore R. B.: A new multipletcluster model for the morphology of random ionomers. Macromolecules, 23, 4098-4107 (1990).

DOI: $10.1021 / \mathrm{ma} 00220 \mathrm{a} 012$

[28] Ibarra L., Rodríguez A., Mora-Barrantes I.: Crosslinking of carboxylated nitrile rubber (XNBR) induced by coordination with anhydrous copper sulfate. Polymer International, 58, 218-226 (2009).

DOI: $10.1002 /$ pi.2519
[29] Ibarra L., Alzorriz M.: Ionic elastomers based on carboxylated nitrile rubber and calcium oxide. Journal of Applied Polymer Science, 87, 805-813 (2003). DOI: 10.1002/app.11468

[30] Ibarra L., Alzorriz M.: Ionic elastomers based on carboxylated nitrile rubber (XNBR) and zinc peroxide: Influence of carboxylic group content on properties. Journal of Applied Polymer Science, 84, 605-615 (2002).

DOI: $10.1002 / a p p .10313$

[31] Mandal U. K., Tripathy D. K., De S. K.: Dynamic mechanical spectroscopic studies on plasticization of an ionic elastomer based on carboxylated nitrile rubber by ammonia. Polymer, 37, 5739-5742 (1996). DOI: $10.1016 / \mathrm{S} 0032-3861(96) 00545-9$

[32] Sahoo S., Bhowmick A. K.: Influence of $\mathrm{ZnO}$ nanoparticles on the cure characteristics and mechanical properties of carboxylated nitrile rubber. Journal of Applied Polymer Science, 106, 3077-3083 (2007). DOI: 10.1002/app.24832

[33] Zhang Y., Liu Q., Zhang Q., Lu Y.: Gas barrier properties of natural rubber/kaolin composites prepared by melt blending. Applied Clay Science, 50, 255-259 (2010).

DOI: $10.1016 /$ j.clay.2010.08.006 